15,09

\title{
Влияние иона комплексообразователя на величину оптической анизотропии лантанидомезогенов
}

\author{
(С) Л.А. Добрун ${ }^{1}$, А.П. Ковшик ${ }^{1}$, Е.И. Рюмцев ${ }^{1}$, Ю.Г. Галяметдинов ${ }^{2}$, А.А. Князев ${ }^{2}$ \\ ${ }^{1}$ Санкт-Петербургский государственный университет, \\ Санкт-Петербург, Россия \\ ${ }^{2}$ Казанский национальный исследовательский технологический университет, \\ Казань, Россия \\ E-mail: I.dobrun@spbu.ru
}

(Поступила в Редакцию 5 июля 2016 г.

В окончательной редакции 29 сентября 2016 г.)

\begin{abstract}
Проведены измерения показателей преломления и оптической анизотропии ряда жидкокристаллических координационных соединений на основе лантаноидов с одинаковым лигандным окружением. Обнаружено, что величина оптической анизотропии исследованных комплексов в несколько раз меньше анизотропии органических жидких кристаллов. Анализ полученных результатов показал, что в мезогенных комплекcax, содержащих одинаковые лиганды, вариация иона комплексообразователя слабо влияет на величину оптической анизотропии. При этом наблюдается четно-нечетная альтернация оптической анизотропии лантанидомезогенов при увеличении количества протонов в ионах лантаноидов.
\end{abstract}

Работа выполнена при поддержке грантов СПбГУ № 11.37.161.2014 и 11.37.145.2014.

DOI: 10.21883/FTT.2017.04.44285.279

В настоящее время интенсивно изучаются и находят широкое практическое применение жидкокристаллические парамагнитные координационные соединения лантаноидов (лантанидомезогены) [1,2]. Лантанидомезогены могут использоваться в различных устройствах оптической электроники, органических светоизлучающих диодах различного цвета, плоских и гибких дисплеях, оптических волноводах, люминесцентных биозондах, гибридных лазерах, солнечных батареях и т.д [3-5].

Эксплуатационные характеристики лантанидомезогенов существенным образом зависят от их физических свойств, таких как магнитная, диэлектрическая и оптическая анизотропия. Для целенаправленного синтеза лантанидомезогенов с заданными параметрами необходимы сведения о взаимосвязи химической структуры, молекулярных характеристик и макроскопических свойств комплексов.

В работах $[6,7]$ было установлено, что величина и знак макроскопической магнитной анизотропии лантанидомезогенов $\Delta \chi=\chi_{\|}-\chi_{\perp}\left(\chi_{\|}\right.$и $\chi_{\perp}-$ компоненты магнитной восприимчивости в направлениях, параллельном и перпендикулярном оси преимущественной ориентации молекул лантанидомезогенов) определяются природой иона комплексообразователя и структурой координационного центра. Значение $\Delta \chi$ может на несколько порядков превосходить анизотропию диамагнитных жидких кристаллов. Первые измерения величины оптической анизотропии $\Delta n=n_{o}-n_{e}\left(n_{e}\right.$ и $n_{o}-$ главные показатели преломления необыкновенного и обыкновенного лучей) лантанидомезогенов показали, что их $\Delta n$ на один-два порядка меньше, чем у органических термотропных жидких кристаллов [8]. Однако ограниченный набор объектов исследования не позволил установить непосредственное влияние иона комплексообразователя и химической структуры лигандов на величину оптической анизотропии лантанидомезогенов. В связи с отмеченным представляется актуальной цель настоящей работы, заключающаяся в экспериментальном определении оптической анизотропии лантанидомезогенов с одинаковым лигандным составом и различными комплексообразователями.

В качестве объектов исследования были использованы жидкокристаллические аддукты трис $(\beta$-дикетонатов) лантаноидов с 5,5'-ди(гептадецил)-2,2'-бипиридином $L n\left(\mathrm{CPDk}_{3-5}\right) \mathrm{Bpy}_{17-17}, \quad$ где $\quad L n=\mathrm{Eu}, \quad \mathrm{Gd}, \quad \mathrm{Tb}, \quad \mathrm{Dy}$; $\mathrm{CPDk}_{3-5}-\beta$-дикетонатон (1-(4-(4-пропилциклогексил)фенил)октан-1,3-дион); Вру $17-17-5,5^{\prime}$-ди(гептадецил)-2,2'-бипиридин (рис. 1). Эти соединения обладают устойчивой энантиотропной нематической фазой в широком интервале температур, что было показано методами дифференциальной сканирующей калориметрии и методом поляризационной оптической микроскопии [9].

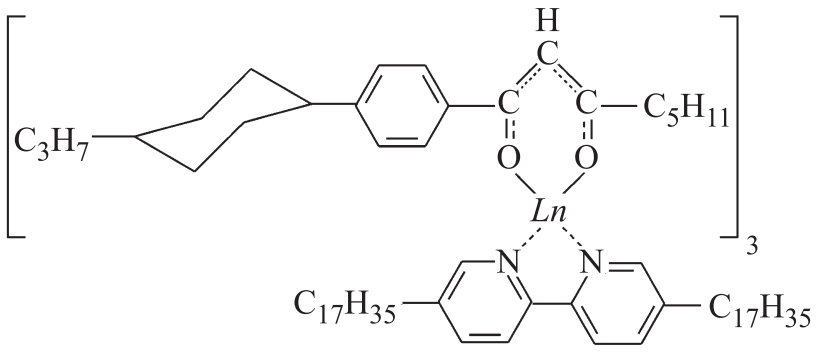

Рис. 1. Структурная формула исследованного ряда лантанидомезогенов. 


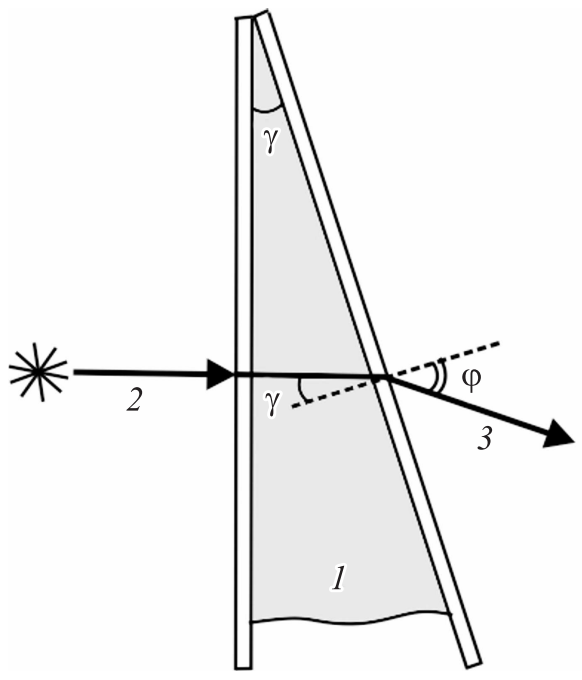

Рис. 2. Схема измерения показателей лантанидомезогенов. 1 - жидкий кристалл, 2 - луч лазера, 3 - преломленный луч.

Измерения показателей преломления комплексов в жидкокристаллическом состоянии и изотропной фазе проводились методом призмы $[8]$ (рис. 2). Клинообразный слой жидкого кристалла помещался между двумя плоскопараллельными полированными стеклами измерительной ячейки. Луч гелий-неонового лазера $(\lambda=632 \mathrm{~nm})$, направленный перпендикулярно на одно из стекол ячейки, проходил через клинообразный слой жидкого кристалла и выходил через второе стекло. Показатели преломления рассчитывались по формуле

$$
n=\frac{\sin \varphi}{\sin \gamma},
$$

где $\gamma-$ преломляющий угол клина, $\varphi-$ угол, образованный выходящим из клина лучом с нормалью к поверхности клина. Для измерения углов $\gamma$ и $\varphi$ использовался гониометр $\Gamma-5$. Точность определения показателей преломления составляла \pm 0.002 . Для получения температурной зависимости показателей преломления и оптической анизотропии исследуемые образцы помещались в термостат. Температура изменялась с помощью подаваемого компрессором нагретого воздуха. Стабильность поддержания температуры составляла $\pm 0.2^{\circ} \mathrm{C}$.

Сильное рассеяние необыкновенного луча в неориентированных образцах затрудняло прямое измерение показателя преломления $n_{e}$. Поэтому экспериментально были определены только величины $n_{o}$ и показатели преломления в изотропной фазе $n_{\text {is. }}$. Главные значения показателей преломления необыкновенного луча $n_{e}$ pacсчитывались с использованием соотношения

$$
n_{\mathrm{is}}^{2}=\left\langle n^{2}\right\rangle=\frac{n_{e}^{2}+2 n_{o}^{2}}{3},
$$

где $\left\langle n^{2}\right\rangle$ является экстраполяцией температурной зависимости показателя преломления $n_{\text {is }}$ в область температур существования жидкокристаллической фазы. Такой способ определения $n_{e}$ также используется при измерении показателей преломления жидких кристаллов методом Аббе, если $n_{e}$ превосходит показатель преломления стеклянных призм рефрактометра [10]. Обоснованность применения соотношения (2) подтверждается многочисленными экспериментальными данными для широкого круга нематических жидких кристаллов, в которых температурная зависимость среднего значения показателя преломления в мезофазе $\langle n\rangle$ с достаточной степенью точности является продолжением температурной зависимости показателя преломления $n_{\text {is }}[10,11]$.

На рис. 3-6 представлены зависимости от температуры экспериментально определенных величин показателей преломления $n_{o}, n_{\text {is }}$ и рассчитанных значений $n_{e}$ исследованных лантанидомезогенов. С исполь-

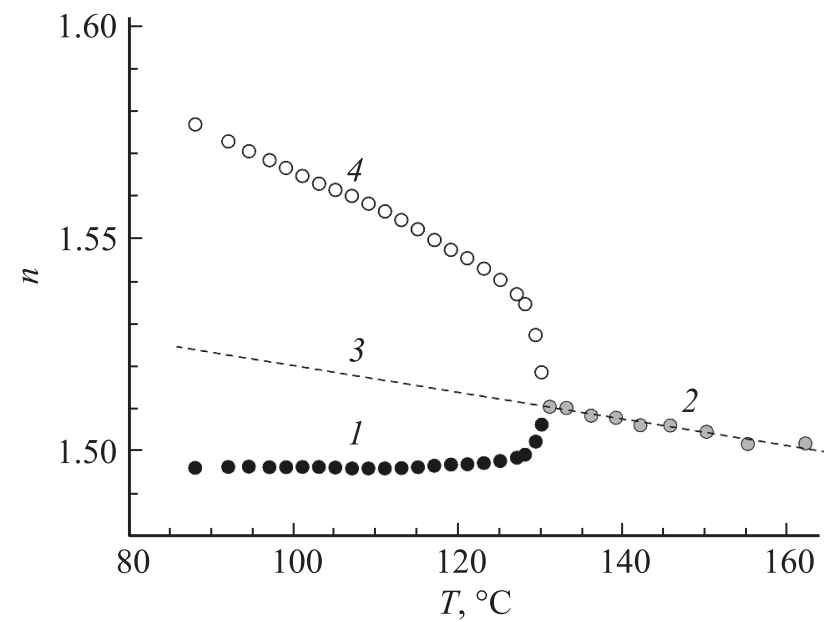

Рис. 3. Зависимость показателей преломления комплекса $\mathrm{Eu}\left(\mathrm{CPDk}_{3-5}\right) \mathrm{Bpy}_{17-17}$ от температуры. $1-n_{o}, 2-n_{\text {is }}$, 3 - экстраполяция $n_{\text {is }}$ в область мезофазы, $4-$ расчетное значение $n_{e}$.

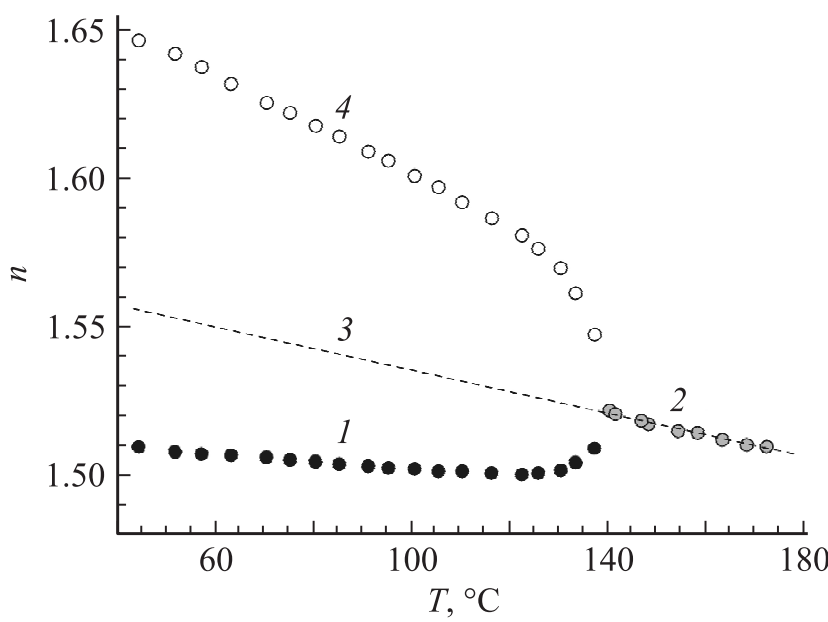

Рис. 4. Зависимость показателей преломления комплекса $\mathrm{Gd}\left(\mathrm{CPDk}_{3-5}\right) \mathrm{Bpy}_{17-17}$ от температуры. $1-n_{o}, 2-n_{\text {is }}$, 3 - экстраполяция $n_{\mathrm{is}}$ в область мезофазы, 4 - расчетное значение $n_{e}$. 


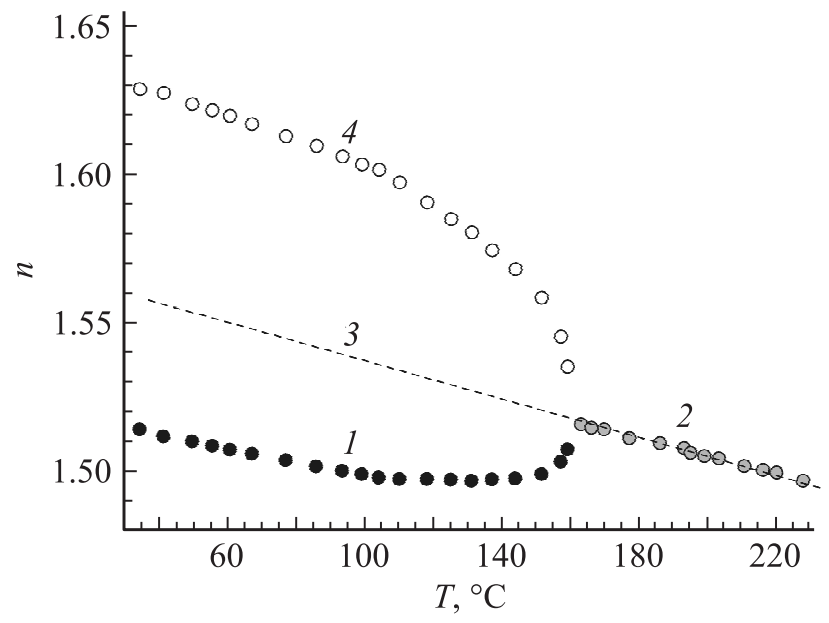

Рис. 5. Зависимость показателей преломления комплекса $\mathrm{Tb}\left(\mathrm{CPDk}_{3-5}\right) \mathrm{Bpy}_{17-17}$ от температуры. $1-n_{o}, 2-n_{\text {is }}$, 3 - экстраполяция $n_{\text {is }}$ в область мезофазы, 4 - расчетное значение $n_{e}$.

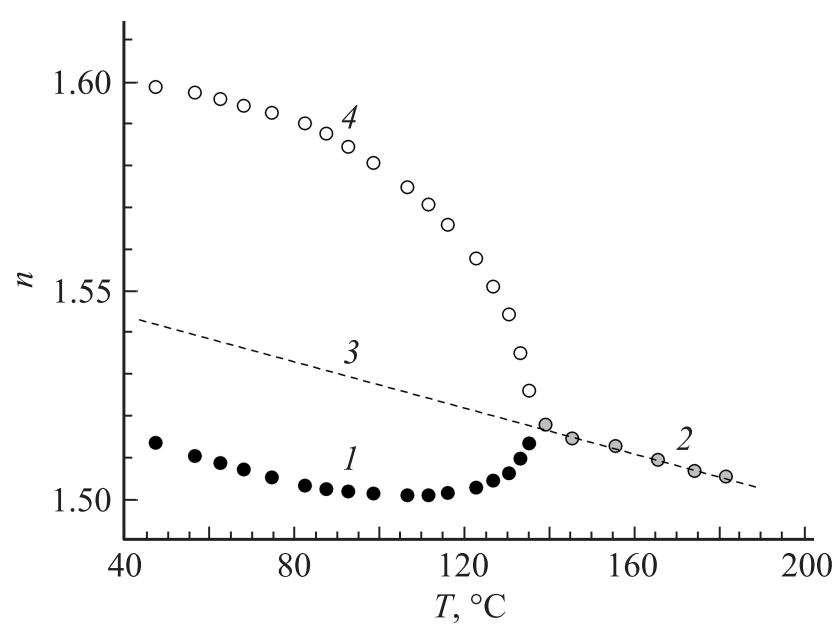

Рис. 6. Зависимость показателей преломления комплекса $\mathrm{Dy}\left(\mathrm{CPDk}_{3-5}\right) \mathrm{Bpy}_{17-17}$ от температуры. $1-n_{o}, 2-n_{\text {is, }}$, 3 - экстраполяция $n_{\mathrm{is}}$ в область мезофазы, $4-$ расчетное значение $n_{e}$.

зованием экспериментальных данных, приведенных на рис. 3-6, были получены значения оптической анизотропии $\Delta n$. Зависимости $\Delta n$ от относительной температуры $\Delta T=T / T_{0}\left(T_{0}-\right.$ температура перехода жидкий кристалл-изотропная жидкость) показаны на рис. 7. Видно, что величины $\Delta n$ исследованных комплексов в интервале существования нематической фазы возрастают от значений 0.015-0.03 вблизи $T_{0}$ до $0.08-0.11$ при $\Delta T=-40^{\circ} \mathrm{C}$ и в среднем в несколько раз меньше анизотропии классических каламитных жидких кристаллов [11-13]. Значения $\Delta n$ при одинаковой относительной температуре $\Delta T=-10^{\circ} \mathrm{C}$ представлены в таблице. Из таблицы следует, что величины $\Delta n$ исследованных лантанидомезогенов находятся в пределах от 0.049 до 0.074 и отличаются от среднего значения $\langle\Delta n\rangle$, равного 0.072, на 12.5\%. Поэтому можно сделать вывод, что вариация комплексообразователя (лантаноида) в жидкокристаллических координационных соединениях с одинаковым лигандным окружением влияет на величину их оптической анизотропии значительно слабее, чем на величину анизотропии магнитной восприимчивости. Действительно, магнитные анизотропии исследованных в работе лантанидомезогенов различаются по знаку и величине (на порядок): $\Delta \chi_{\mathrm{Eu}} \approx-1.3 \cdot 10^{-3} \mathrm{~cm}^{3} / \mathrm{mol}$, $\Delta \chi_{\mathrm{Gd}} \approx 1.8 \cdot 10^{-3} \mathrm{~cm}^{3} / \mathrm{mol}, \Delta \chi_{\mathrm{Tb}} \approx-12 \cdot 10^{-3} \mathrm{~cm}^{3} / \mathrm{mol}$, $\Delta \chi_{D y} \approx-14 \cdot 10^{-3} \mathrm{~cm}^{3} / \mathrm{mol}$ [14]. Для более наглядного представления влияния вариации иона комплексообразователя на величину оптической анизотропии лантанидомезогенов на рис. 8 показана зависимость $\Delta n$ от $Z-$ числа протонов в атоме лантаноида при $\Delta T=-10^{\circ} \mathrm{C}$. На рис. 8 обращает на себя внимание четно-нечетная альтернация $\Delta n$ с ростом $Z$. При этом значения $\Delta n$

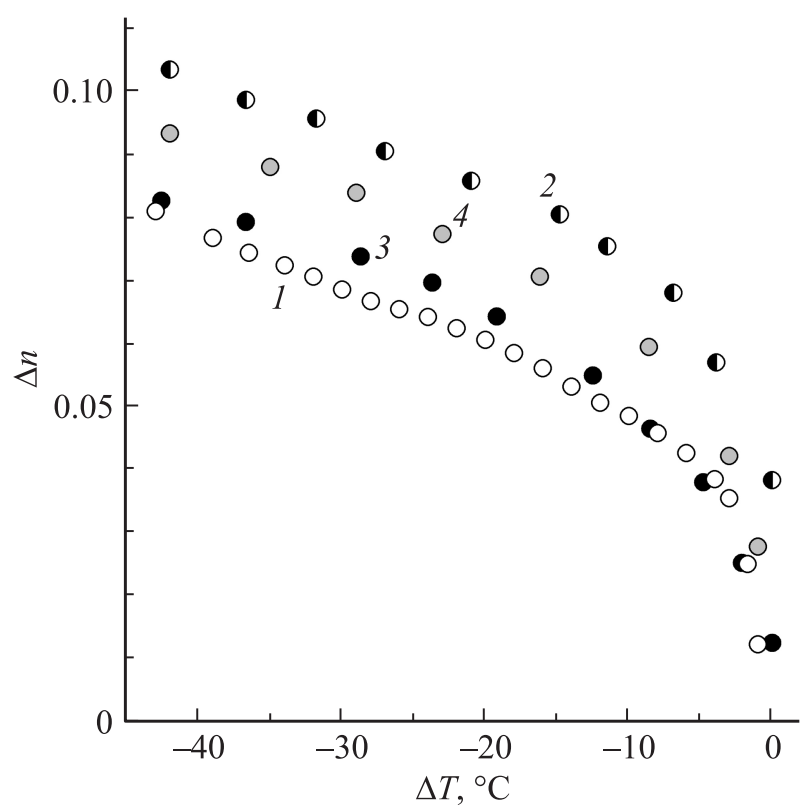

Рис. 7. Зависимость оптической анизотропии $\Delta n$ от относительной температуры $\Delta T .1-\mathrm{Eu}\left(\mathrm{CPDk}_{3-5}\right) \mathrm{Bpy}_{17-17}$, $2-\mathrm{Gd}\left(\mathrm{CPDk}_{3-5}\right) \mathrm{Bpy}_{17-17}, 3-\mathrm{Tb}\left(\mathrm{CPDk}_{3-5}\right) \mathrm{Bpy}_{17-17}$, $4-\mathrm{Dy}\left(\mathrm{CPDk}_{3-5}\right) \mathrm{Bpy}_{17-17}$.

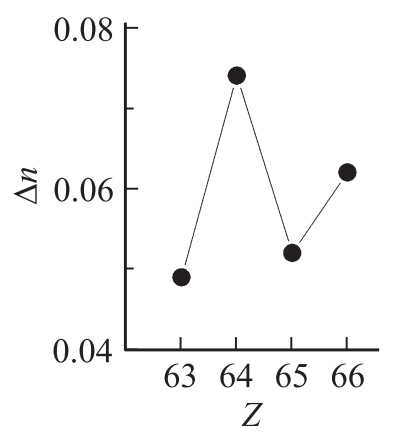

Рис. 8. Зависимость оптической анизотропии $\Delta n$ от числа протонов $Z$ в ионе комплексообразователя при $\Delta T=-10^{\circ} \mathrm{C}$. 
Сокращенные обозначения, количество протонов, температуры фазовых переходов $T_{0}$, оптические анизотропии при $\Delta T=-10^{\circ} \mathrm{C}$ для исследованных комплексов

\begin{tabular}{c|c|c|c}
\hline Название & $Z$ & $T_{0},{ }^{\circ} \mathrm{C}$ & $\Delta n$ \\
\hline $\mathrm{Eu}\left(\mathrm{CPDk}_{3-5}\right)_{3} \mathrm{Bpy}_{17-17}$ & 63 & 131 & 0.049 \\
$\mathrm{Gd}\left(\mathrm{CPDk}_{3-5}\right)_{3} \mathrm{Bpy}_{17-17}$ & 64 & 137 & 0.074 \\
$\mathrm{~Tb}\left(\mathrm{CPDk}_{3-5}\right)_{3} \mathrm{Bpy}_{17-17}$ & 65 & 137 & 0.052 \\
$\left.\left.\mathrm{Dy}_{(\mathrm{CPDk}}\right)_{3-5}\right)_{3} \mathrm{Bpy}_{17-17}$ & 66 & 160 & 0.062
\end{tabular}

лантанидомезогенов на основе ионов с четным числом протонов превышают $\Delta n$ с нечетным $Z$. Хорошо известно, что четно-нечетные эффекты характерны для физических свойств гомологических рядов классических жидких кристаллов. Например, подобным образом изменяются температуры фазовых переходов $T_{0}$ и анизотропия рефракции $\Delta R$ в зависимости от количества групп $\mathrm{CH}_{2}$ в алифатических радикалах молекул жидких кристаллов [11-13]. Для подтверждения наличия четнонечетного эффекта при вариации количества протонов в атомах лантаноидов необходим синтез жидкокристаллических комплексов на основе других ионов лантаноидов с данной лигандной оболочкой, а также исследование их оптических свойств.

Различия $\Delta n$ исследованных жидкокристаллических координационных соединений, обнаруженные при замене иона комплексообразователя, обусловлены изменениями как молекулярных свойств, так и структурной упорядоченности среды. Оптическая анизотропия лантанидомезогенов может быть связана с анизотропией поляризуемости комплексов $\Delta b=b_{1}-b_{2}\left(b_{1}\right.$ и $b_{2}-$ поляризуемости вдоль продольной и поперечной осей комплекса) и степенью ориентационного порядка $S$ следующим соотношением [8]:

$$
\left(n_{e}-n_{o}\right)=\Delta n=\frac{\langle n\rangle^{2}+2}{n_{e}+n_{o}} \frac{4}{3} \pi \frac{\rho}{M} N_{A} \Delta b S .
$$

Здесь $M-$ молекулярная масса, $\rho-$ плотность, $N_{A}-$ число Авогадро.

Очевидно, что анизотропия поляризуемости исследованных комплексов $\Delta b$ определяется электрической и пространственной структурой координационного центра, поскольку химическое строение, а также количество лигандов, входящих в их состав, совершенно одинаково. Причиной различия структур координационных центров лантанидомезогенов, по-видимому, являются изменения заполненности $f$-орбитали и радиуса иона лантаноида, происходящие при изменении числа протонов в ряду лантаноидов. Эти же факторы могут изменять и степень ориентационного порядка. Вопрос о степени влияния на величину $\Delta n$ анизотропии поляризуемости $\Delta b$ и ориентационного порядка $S$ является предметом дальнейшего исследования.

Таким образом, исследования оптических свойств ряда термотропных нематических жидкокристаллических комплексов на основе ионов $\mathrm{Eu}, \mathrm{Gd}, \mathrm{Tb}, \mathrm{Dy}$ с одинаковым лигандным окружением показали, что вариация иона комплексообразователя влияет на величину оптической анизотропии значительно слабее, чем на магнитную анизотропию. Обнаружен четно-нечетный эффект в зависимости оптической анизотропии исследованных лантанидомезогенов от числа протонов, содержащихся в ионах комплексообразователя. Показано, что причиной зависимости оптической анизотропии от количества протонов в атоме комплексообразователя в ряду лантанидомезогенов с однотипными лигандами являются изменения молекулярной анизотропии поляризуемости и степени ориентационного порядка, связанные с изменением структуры координационного центра.

Результаты работы демонстрируют необходимость дальнейших исследований оптических свойств лантанидомезогенов с более широкой вариацией ионов комплексообразователя.

\section{Список литературы}

[1] K. Binnemans. In: Handbook on the physics and chemistry of rare earths. Elsevier (2013). V. 43, P. 1.

[2] О.Н. Кадкин, Н.Е. Домрачева, И.В. Овчинников. Жидкие кристаллы и их практическое использование 15, 21 (2015).

[3] J. Feng, H. Zhang. Chem. Soc. Rev. 42, 387 (2013).

[4] N.T. Kalyani, S.J. Dhoble. Renewable Sustainable Energy Rev. 44, 319 (2015).

[5] H. Xu, Q. Sun, Z. An, Y. Wei, X. Liu. Coord. Chem. Rev. 293, 228 (2015).

[6] V.S. Mironov, Yu.G. Galyanetdinov, A. Ceulemans, C. GorllerWalrand, K. Binnemans. Chem. Phys. Lett. 345, 132 (2001).

[7] V.S. Mironov, Yu.G. Galyametdinov, A. Ceulemans, K. Binnemans. J. Chem. Phys. 116, 11 (2002).

[8] А.П. Ковшик, Е.С. Крайнюков, С.А. Ковшик, А.А. Князев, Ю.Г. Галяметдинов, Е.И. Рюмцев. Опт. и спектр. 116, 61 (2014).

[9] V.I. Dzhabarov, A.A. Knyazev, M.V. Strelkov, E.Yu. Molostova, V.A. Schustov, W. Haase, Yu.G. Galyametdinov. Liq. Cryst. 37, 285 (2010).

[10] S. Sen, P. Brahma, S.K. Roy, D.K. Mukherjee, S.B. Roy. Mol. Cryst. Liq. Cryst. 100, 327 (1983).

[11] В.Н. Цветков, Е.И. Рюмцев, И.П. Коломиец, А.П. Ковшик, Н.А. Ганцева. Опт. и спектр. 35, 880 (1973).

[12] В.Н. Цветков, Е.И. Рюмцев, А.П. Ковшик, И.П. Коломиец. Кристаллография 18, 1246 (1973).

[13] А.П. Ковшик, В.Н. Цветков, Е.И. Рюмцев, Ю.И. Дените. Кристаллография 20, 861 (1975).

[14] А.А. Князев. Полифункциональные лантаноидсодержащие жидкие кристаллы: молекулярное строение и физикохимические свойства. Докт. дис. КНИТУ, Казань (2012). $300 \mathrm{c}$. 